DOI: $\underline{10.20472 / T E .2018 .6 .2 .006 ~}$

\title{
IMPLEMENTING COMPREHENSIVE INTERVENTIONS TO SUPPORT STUDENT SUCCESS IN ONLINE LEARNING
}

\author{
HWANGILU
}

\begin{abstract}
:
The innovation and maturity of education technology has enabled online learning to be more accessible and manageable than ever before. Online education becomes so appealing as programs of study can be pursued with the flexibility in time and space. However, the most pressing challenge posed is student attrition that has significant quality and economic impacts on online institutions. In response to the negative influences brought by high dropout rates, educational institutions have striven to implement strategies to improve students' learning experiences and assist them in successfully achieving their academic goals. The goal of this paper is to examine institutional practices, resources, strategies that are needed to ensure sustainability in the online education. This paper first reviews Tinto's student integration model as the theoretical framework. This paper presents a survey of literature to highlight significant factors that lead to students' decision on withdrawal from a course or program. This paper also summarizes an assortment of evidence-based practices in relation to student retention. Finally, a case study is presented to examine the implementation of interventions in an online university. Student persistence is a vital part of the institution's survival. A continuing monitoring and evaluation system plays a key role in improved student satisfaction and success.
\end{abstract}

\section{Keywords:}

online learning, student retention, drop-out rate, student persistence, student success, withdrawal behavior

JEL Classification: 129

\section{Authors:}

HWANGJI LU, Ashford University, United States, Email: hwangji.lu@Ashford.edu

\section{Citation:}

HWANGJI LU (2018). Implementing Comprehensive Interventions to Support Student Success in Online Learning. International Journal of Teaching and Education, Vol. VI(2), pp. 87-107., 10.20472/TE.2018.6.2.006 


\section{Introduction}

Advances in computer-mediated communication technologies have changed the educational landscape. In the higher education, the proliferation of online courses and programs continues to be a significant trend as an alternative to the traditional, face-to-face learning. This learning modality offers the students, greater convenience, flexibility, costeffectiveness, work-life-school balance (Travers, 2016) and the opportunity to complete the degree anywhere and anytime (Bowers and Kumar, 2015; Lu, 2017). Additionally, increasing demand from non-traditional, working adults who have both professional, family, and social responsibilities has driven the growth in online learning (Cochran, Cambell, Baker, and Lees, 2014). Because of its convenience, online education has become a crucial component of higher education. The U.S. Department of Education's National Center for Education Statistics (NCES) has tracked and reported data on postsecondary enrollment in distance education since 2012. According to the latest enrollment data released from NCES, in the Fall 2016 term, 31.2\% of all students were taking at least one distance learning course, which is higher than 29.3\% in 2015 (Hill, 2018). Students who were taking a combination of distance and non-distance courses in Fall 2016 accounted for $16.5 \%$ of all higher education enrollments while $14.7 \%$ of the students enrolled exclusively in distance learning courses or programs.

As defined by Southern Regional Education Board (n.d.), adult learners, often referred as nontraditional students, are those learners over the age of 25 , spanning a wide range of abilities, educational and cultural backgrounds, responsibilities, and job experiences. Adult learners are unable to enroll in traditional programs due to other responsibilities at home and/or work. They often juggle the schoolwork along with the demands of the job, family, and other life commitments (Southern Regional Education Board, n.d.) Due to the characteristics of adult learners, high attrition rates are unexceptional to the online environment (Cochran et al., 2014; Thomas, Herbert, and Teras, 2014). The rates were 10 to $20 \%$ higher than those of face-to-face classes (Bart, 2012; Cochran et al., 2014). High attrition rates have significant economic and quality impacts on the educational institutions (Britto and Rush, 2013).

In today's competitive and economically charged marketplace, educational institutions cannot afford to be reactive to the needs of online students; rather, they need to proactively develop a strategic vision and plan to ensure online students have the best experience possible. Moreover, government and accrediting agency bodies are also placing a greater emphasis on student retention and learning outcomes (Poll, Widen, and Weller, 2014). Since higher educational institutions rely on government and state funding, they must meet certain standards when it comes to retention and persistence, and not meeting those standards can cause institutions to lose thousands of dollars in funding (Conner, Daugherty, \& Gilmore, 2013). Thus, raising retention rates would also help institutions to surmount revenue losses, the associated resource planning issues, and damaging 
perceptions of education quality (Cochran et al., 2014). It is also important for institutions to find out why some students are leaving and why other students stay and persist. Therefore, the objective of this paper is to explore institutional policies, practices, resources, and strategies that will ensure the institution's sustainability in the competitive online learning environment.

The remainder of this paper is organized as follows. First, theoretical framework presents an examination of Tinto's student integration model. Second, literature review summarizes factors impacting retention in online education and strategies for better retention and online experience. Third, a case study portrays a U.S. University's efforts in coping with high attrition rates. Fourth, a discussion focuses on presenting the leadership's commitments and efforts to the University's viability in the case study. Fifth, a conclusion ends with the final thoughts and suggestions.

\section{Theoretical Framework}

Student retention has impacted on the revenue and perception of quality education in the colleges and universities. Over the past few decades, there are several different theories from various disciplines including managerial science, educational psychology, and social psychology used to study retention. In this paper, the literature review specifically focuses on Tinto's student integration model that provides an experiential and theoretical framework for investigating retention (Tinto 1975; Tinto 1987; Tinto 1993).

Vincent Tinto first introduced his view of retention in 1975. Tinto (1975) postulated that a student's persistence is strongly associated with his/her academic experiences and social integration. According to Tinto's student integration model, a combination of student characteristics and the extent of his/her academic, environmental, and social integration in an institution can predict whether a student will decide to drop out of school (Demetriou and Suhmitz-Sciborski, 2011). Tinto (1975) posited that there are two dimensions of student integration into an institution: the academic and social. Academic integration happens when students become attached to the intellectual life of the institution; on the other hand, social integration arises as students establish the relationships and connections outside of the classrooms. These two integrations enhance one another, which can be promoted by both formal and informal systems within the institutions (Tinto, 1975). Once students are integrated into the institution along with both dimensions, the likelihood of persistence will be increased. In Tinto's (1975) viewpoints, to persist, students need integration into four systems: the formal academic system, informal academic system, formal social system, and informal social system. The formal academic system is composed of academic performance; faculty and staff interactions are included in the informal academic system; and the formal social system contains extracurricular activities while the informal social system refers to peer-group interactions (Tinto, 1975). The degree 
of success that students have in their pursuit of higher education affects the students' commitment to the institution, academic goals, and career goals.

During the 1980s and 1990s, Tinto continued his research and revised the student integration model many times over the decades since it was originally proposed. According to Tinto's (1987) theory, academic and social integration are complementary but standalone processes in any student's life. Tinto (1987) observed that students' failure to become incorporated into the intellectual and social life of the institution, often, initiates their decision of withdrawal from the institution. Without a double, students tend to leave their academic lives while performing poorly (Demetriou and Suhmitz-Sciborski, 2011). Apart from academic difficulty, Tinto (1987) suggested six other reasons as to why students leave, including adjustment, commitments, goals, uncertainty, congruence, and isolation. The adjustment issues come in the early part of student's academic career. As Tinto (1987) stated, difficulty transitioning into the new learning community and the inability to incorporate into the new school life could be due to students' inability of taking on the demands that college places on them or their social immaturity to adjust to college life. Tinto (1987) pointed out that if there is a big difference between students' previous learning environment and the new learning community, students might not be willing or able to adjust to the new academic and social life of the higher education. Additionally, adjustment becomes a problem when the student does not possess the coping skills needed for adapting the life in the new learning community.

It is a longitudinal process that students' entry commitment influences the extent of their integration as well as their academic and social interactions within an educational institution, which in turn has an impact on their goals and institutional commitments. Some students might not have the commitment to finish their college or they might change their commitment due to various reasons, so that they eventually leave the educational institution without completing their degrees (Tinto, 1987). In line with commitment, Tinto (1987) noted that the lack of goals also contributes to the student's determination of dropping out of the college. If the students go to college without clear goals in mind or they have goals that differ from those of the college, they are inclined to drop out of the institution. Tinto (1987) stated that sometimes individual's goals could also change from time to time, which is another reason as to why students leave (Tinto, 1987). Uncertainty, as Tinto (1987) perceived, is another issue that triggers students to leave along with commitment or goal issues. Tinto (1987) also argued that incongruence and isolation are other reasons why students do not complete their degree. Incongruence with the college occurs when students feel that college is not a good fit for them, or does not cogitate their idea, or does not have the academic rigor. Finally, a student is more likely to leave when he/she feels a lack of social interaction between the individual student and other students or academic staff or professors at the institution (Tinto, 1987). 
During the 1990s, much retention literature turned the attention to understand student transition periods, especially the first-year experience; therefore, research and best practices emphasized on the collaboration across different departments in the institution (Demetriou and Suhmitz-Sciborski, 2011). In order to provide quality support services, Tinto (1999) suggested that academic advising should be integrated into a student's firstyear experience to support student development. The holistic approaches and initiatives designed to support student retention should stress on cross-department responsibility and address both formal and informal student experiences in the intellectual and social life of the institution.

As more research studies were developed, Tinto (1993) further identified different student groups, such as African American students, students from low-income families, adult students, and transfer students. Indeed, each group with unique experiences demands group-specific interventions and policies (Tinto, 1993). Tinto (1993) argued that to serve a diverse student population, there is a need to match student's expectations to institutional mission and facilitate the transitions of students moving through the college process. In order to improve student retention, institutions of higher education ought to provide easily accessible academic, personal, and social support services (Tinto, 2007). The interactions that a student has with individuals working in academic, administrative, and support service centers would determine the student's sense of connection to the university and his/her competence to navigate the institutional culture, meet the expectations, and succeed academically. A student is more likely to graduate from a college or university that embraces high expectations and actively involves the student in the learning process (Demetriou and Suhmitz-Sciborski, 2011). Likewise, students are less likely to remain in the institution as they feel isolated, do not engage in social interactions within the college, or do not believe that the institution can help them meet their goals.

Overall, a student's persistence or drop-out is strongly predicted by his/her degree of academic integration and social integration (Tinto, 1999; Tinto, 2007). Students depart from higher education for many reasons that could be due to individual student and/or institutional issues, including given attributes, skills, financial resources, prior educational experiences, dispositions (intentions and commitments), and integration with other members of the academic and social systems in the institution (Tinto, 1993). It is recommended by Tinto (2007) that institutions should deliberately incorporate students into the institution's culture. Institutions are obliged to create opportunities for extracurricular activities, informal student interactions with peers, and faculty/student interactions to fulfill students' academical, intellectual, and social needs. 


\section{Literature Review}

Previous empirical studies concerning student retention have identified a wide range of variables. Each of the variables could have direct and indirect impacts on student's ability or desire to graduate. This section will first discuss key factors that impact student retention in the online environment. This section will also present the strategies for improving student retention that are compiled from a survey of the literature.

\subsection{Factors Impacting Retention in Online Education}

Student retention in online education continues to receive lots of attentions from researchers, educators, and institutions. Retention is a complex and multi-dimensional issue (Rovai and Downey, 2010). Review of existing literature indicates that a learner's decision to withdraw could stem from a wide variety of explanations including motivational, social, and technological issues existing from both the personal and institutional perspectives (Tinto, 1987; Travers, 2016). It is an intricate process to identify the correlations among the factors that influence attrition in online courses. There appears to be no a simple solution that can solve the problems and help all learners complete their educational goals.

\subsubsection{Personal Variables}

Keeping students engaged and enrolled in online classes is a challenge. Bawa (2016) argued that one of the biggest deterrents to online retention is the overestimation of student capabilities with respect to the demands of time, commitment, and technological skills required in online learning. Taipjutorus, Hansen, and Brown (2012) also considered learners' confidence in their study ability as an important factor in determining the success of the online study.

Research studies (Cochran et al., 2014; James, Swan, and Daston, 2016; Lee and Choi, 2013; Tino, 1987; Travers, 2016) have identified that inadequate academic preparation for the online learning environment contributes to the low retention rate substantively. Inadequate preparation leads to academic difficulty, which means the students are not able to meet minimum academic standards of an institution. Consequently, students cannot attain their educational goals. In addition, many online students who returned to school in their later lives have been disconnected to the formal education environment for years; thus, they are no longer accustomed to the formal learning setting (Demetriou and SuhmitzSciborski, 2011; Travers, 2016). They need to relearn the basics and overcome the learning curve in order to continue their studies. Furthermore, many of these students may have under-performance in school, which potentially arises from lower socioeconomic populations who come from a lower standard at their previous educational level, be single 
or married parents with plentiful family obligations, and hold multiple jobs in either full-time or part-time employment (Demetriou and Suhmitz-Sciborski, 2011; Travers, 2016). These students typically have weaker academic preparation and fewer economic resources than students at other more selective colleges and universities.

The varying characteristics of non-traditional students is a major influence on retention in online courses (Travers, 2016). In Xu and Jaggars's (2014) study, they explored the effect of age, ethnicity, gender, and previous academic performance to ascertain how these characteristics affected performance and retention in online and traditional courses. The findings from this research revealed that males, African Americans, Hispanics, and underprepared students performed considerably worse in online courses than campus courses (Xu and Jaggars, 2014). Hispanic and African American students tend to have the low socioeconomic status that may have the impact on academic preparedness as $\mathrm{Xu}$ and Jaggars' (2014) suggested. This study also showed that compared to younger students, older students have a tendency to perform better in online courses. Xu and Jaggars (2014) advised that self-motivation and self-regulation might also play a key role in their finding. In a survey, the academic leaders reported and believed that online students need more discipline to succeed in and complete their online degree programs (Allen and Seaman, 2015). These leaders deemed that self-motivation and emotions of the learners are key factors that impact retention.

Online courses require students to possess different capabilities from those needed to succeed in the traditional classroom (Travers, 2016). With respect to online education, student readiness factors comprise individual attributes, for example motivation (Demetriou and Suhmitz-Sciborski, 2011), life aspects, technical competency and knowledge, learning styles, ability in reading and recall, as well as typing speed and accuracy (Bowers and Kumar, 2015). Regarding academic preparedness, Xu and Jaggars (2014) found that students who are less prepared frequently wrestle with online coursework and withdraw at higher rates when comparing to those students who are academically prepared. Conner et al. (2014) discovered that $15-25 \%$ of students leave an institution of higher education due to academic hardship.

Technological challenges such as computer literacy, information and communications technology (ICT) navigation skills, ICT resource availability, and greater electronic connection capabilities are also some examples illustrating possible barriers to student retention (Safford and Stinton, 2016; Taipjutorus et al., 2015). In order to participate in class discussion and submit the assignments, students must obtain the basic technology skills on the top of learning the course materials. Often at the beginning of the learning process, online students are excited and worried about this new learning format. In fact, navigating the online format could be a burden on students. Jaggars (2011) alluded that technical difficulties could increase social distance, which, in turn, initiate students' struggle in online courses. 


\subsubsection{Institutional Variables}

Several institutional variables appear to affect persistence rates in online courses, including lacking effective interventions-such as counseling, training, student support (Britto and Rush, 2013; Jaggars, 2011; Nash, 2015; Simonson, Smaldino and Zvacek, 2015)_poorly designed courses (Christensen and Spackman, 2017), and substandard or inexperienced instructors (Travers, 2016). In reviewing the research by Jaggars (2011) and Nash (2015), students drop or fail online courses often due to the lack of off-campus prompt supports from instructors and tutors that are difficult for students to access at a distance. Moreover, at many online universities, one of the main issues is the teaching workload of faculty that might negatively impact online learning (Travers, 2016). When an overloaded faculty teaches courses, he/she has little extra time to dedicate to the effective online instruction; consequently, it exacerbates the negatives brought to the course by the underprepared students (Leist and Travis, 2010; Travers, 2016).

\subsubsection{Lack of a Sense of Community}

Learning is a social process. Interaction has long been considered as a critical component of the educational process (Demetriou and Suhmitz-Sciborski, 2011). Unlike students taking campus classes, students in the online classroom interact with their peers and instructors via the use of information and communication technology. They are responsible for their own learning because they won't be able to rely on the direct interaction with their instructors, peers, and other campus resources (Travers, 2016). Theoretically, students should feel comfortable communicating and expressing themselves. They need to feel connected with the course, their peers, and their instructor. Nevertheless, online learners often feel isolated and disconnected.

In the online learning community, students are supposed to share their ideas, struggles, and successes with others and feel being connected. Students' sense of belonging, their involvement, and their fitness in the learning community are all important factors in remaining in school. Achieving these goals is more difficult in the distance learning setting (Travers, 2016). A lack of feeling of community appears to be one key factor influencing attrition in online courses (Travers, 2016). As Safford and Stinton (2016) believed, the feeling of isolation and anxiety affects the student's decision about dropouts. It is a challenge for online instructors to create a learning environment that supports the diverse identities and experiences of students and foster constructive and respectful dialogue and exchange. On account of an intensive review of the literature, Bowers and Kumar (2015) advised that students with a low perceived sense of connectedness and instructor presence are more likely to drop out online courses. Therefore, social presence is a key determinant in learner's online learning. 


\subsection{Strategies for Better Retention and Online Experience}

Regardless of each student's individual academic goals, universities must continue to improve student retention in distance learning. As suggested by Lee and Choi (2013), to improve student retention, universities should understand students' challenges and potentials, provide quality course activities and well-structured supports, and handle environmental issues and emotional challenges. The influential research by Tinto (1975, 1993) on student retention demonstrated that the greater the level of academic and social integration, the greater the student's chances of persistence to complete the degree. Many other research studies have endorsed Tinto's findings. It is believed that an integrated and ongoing system with pre-course strategies, active in-course strategies, and post-course strategies in instruction and administration would improve student persistence and benefit distance education programs (Lee and Choi, 2013; Nash, 215; Travers, 2016).

\subsubsection{Orientation Programs}

To address the challenges of high attrition rates, online universities can support students by integrating orientation programs to help students become accustomed to online learning and introduce them to the higher education (Britto and Rush, 2013; Travers, 2016). The orientation program is a great way to prepare adult learners with capabilities of taking online courses, so that students will realize the rigors and unique demands of the online courses (Bawa, 2016). A comprehensive course orientation at the beginning of the course or program could increase previously unsuccessful students' sense of confidence to success in the online environment. The online orientations should include the information on what students can anticipate in the online environment and the academic supports available to them. These orientations can also be used as an informal welcome to the students, so that a bond can be created between the students and the institution (Britto and Rush, 2013). Constructing a supportive environment and providing a sense of inclusion in the academic community will help promote student's self-motivation (Britto and Rush, 2013). Some students might show resistance to the orientation program in which they perceive as an unnecessary intervention to their course penetration. Instead of feeling upset about student's attitude, instructors and institutions must contemplate strategies to enforce the orientation program. Strategies might include making the orientation program mandatory or be a part of the entry-level course.

\subsubsection{Course Design}

Nash (2015) advised that it is essential to increase the academic rigor of online education lest it results in the discrediting of educational institutions. One way to raise the academic 
rigor is to enhance online course instructional design. Online learning is thought to promote constructivist thinking and provide students with deep-learning opportunities to think critically, make connections, and share examples of their learning (Poll, Widen, and Weller, 2014). The literature indicates that instructional design at the program and course level does have an influence on student learning and persistence (Burns, 2013; Creelman and Reneland-Forsman, 2013). Effective course designs can offer students the opportunities to make choices for adopting personal learning strategies. Well-structured, deep-learning discussion questions should be constructed to prompt metacognitive responses of learning, application, and reflection from students (Christensen and Spackman, 2017). The online course design should use a systems-based approach to evaluate students as needed, and educational technologies should also be appropriately chosen. The online course design needs to be modified based on ongoing formal and informal assessments completed through various student and instructor interactions. It is also imperative that course redesign will reflect upon the market force and demand.

\subsubsection{Learning Community}

While students drop out of higher education for a variety of reasons, promoting belonging and inclusion in the learning community has a key role in improving retention by motivating students to continue studying (Poll et al., 2014). Learning is an iterative process of dialogue and exchange among the members in the community. The construction of knowledge is thought to be intertwined with personal and group efforts (Nandi, Hamilton, Harland, and Mahmood, 2015) and individual members accomplish a level of cognitive resonance in which they integrate their beliefs and real-world experiences into their personal narratives (Poll et al., 2014; Thomas et al., 2014). Adult learners need to feel that they are part of a learning community, their contributions to the community are acknowledged and incorporated, and their participation and insights are valued (Ritter, Polnicka, Fink, and Oescher, 2010). These aspects develop when students are encouraged to nurture collaborative learning relationships with other members in the learning community. A student with a positive perception of social presence who maintains a high degree of interaction and collaboration with his/her peers is likely to successfully complete an online course with a good grade (Demetriou and Suhmitz-Sciborski, 2011; Liu, Gomez, and Yen, 2009; Thomas et al., 2014).

Numerous research studies have affirmed that online interaction-a critical feature of online teaching and learning — becomes a strong predictor of student achievement and has a positive influence on perceived learning, grades, and quality of their work (Nandi et al., 2015). Discussion forums, assigned peer essay reviews and workshops, and small group work are approaches used to nurture a sense of community in the asynchronous courses (Poll et al., 2014). Peer interaction in the online classroom helps support student learning, build community, and support persistence (Thomas et al., 2014; Tinto, 1975). Frequent 
communication between student-instructor and student-student decreases the feeling of isolation, substantiates academic and social integration, and improves student retention (Demetriou and Suhmitz-Sciborski, 2011; Tinto, 1975). Creating a sense of belonging can engage students in course content, course discussion, and their peers and instructor, promote a successful learning experience, and eventually improves retention (Poll et al., 2014; Thomas et al., 2014).

\subsubsection{Instructor's Interventions}

Instructor's intervention has become more prominent in facilitating a sense of community in an asynchronous setting (Lammers and Gillaspy, 2013). As it is recommended, at the beginning of the course, instructors should set the expectations for interactions that encourage collaboration, equity, respect, and sharing of multiple perspectives in the discussion, dialogue, and conversation (Poll et al., 2014; Nandi et al., 2015; Nash, 2015). The clearly defined expectation of interactions sharps students' engagement in discussions because consistent participation boosts student learning (Nandi et al., 2015). Nandi and colleagues' (2015) research study investigated participation and quality of online interaction, indicating that students highly value their instructor's periodic feedback in the discussion boards, which keeps their discussions on track. Nandi et al. (2015) suggested that periodic feedback can foster meaningful dialogue, encourage collaboration, and create a sense of community for a shared learning purpose. Similar to the face-to-face classroom, the instructor needs to model the desired tone for students to mimic. Much of student success rests on the open learning environment that embraces respect and trust, welcomes diverging perspectives, provokes inquiry, and prompts engaging dialogue (Nandi et al., 2015). With instructor's modeling, the sense of community and accountability among the students can arise naturally, and it positively frames the way how the learning community members tender their insights and manage their interactions in relation to the course content and material (Ritter et al., 2010).

Student learning and satisfaction highly depends on an instructor's continuing presence in the online classroom (Bowers and Kumar, 2015; Poll et al., 2014). Effective communication practices keep instructors consistently present and available to students, which should initiate even before the class begins and continues throughout the course. The instructor needs to establish the rapport as he/she engages in immediacy behaviors with either verbal or nonverbal cues that convey the instructor's caring, concern, interest, and encouragement (Lammers and Gillaspy, 2013). It has been suggested that a predictive relationship exists between rapport and positive student learning outcomes (Lammers and Gillaspy, 2013). Lee and Choi (2013) contended that faculty's engagement, delivery of online content, and support are important elements in student persistence. The high level of instructor's social presence and interaction leads to better learning outcomes. 
It is also a best practice to build the rapport deliberately in online courses in order to continually engage and motivate students (Lammers and Gillaspy, 2013). Bowers and Kumar (2015) recommended that carefully designed interactions such as student to instructor interaction as well as ongoing timely and useful feedback provided by the instructor are critical to reducing attrition rates. Based upon their experience in teaching online, Poll, Widen and Weller (2014) observed that student engagement correlates positively with learning outcomes and retention. Several strategies that can help the instructors achieve the purposeful interactions are an introductory video, welcoming e-mail, prompt responses to students' e-mails and questions posted in the classroom, and e-mails sent throughout the entire course (Lammers and Gillaspy, 2013). It is important to note that the welcome email should reflect upon an instructor's teaching style to begin building relationships with students. Furthermore, the instructor can show his/her care about students' learning, treat students with respect and impartiality, be approachable and available, and have realistic expectations. Alternatively, with the advance in information communication technology (ICT), the instructors may utilize various software applications such as AdobeConnect, Blackboard Collaborate, Citrix WebEx, and Zoom Video Communications to engage students and create a learning environment resembling a traditional face-to-face class (Lu, 2017; Thomas et al., 2014). ICT offers students the opportunity to have virtual real-time conversations with their peers and instructor. ICT also allows students to hear and see their peers and instructor "live," which generates the immediacy and personalized interactions among members in the learning community.

\subsubsection{Instructor's Professional Development}

Nash (2015) asserted that instructors who teach online courses need to be properly trained in strategies pertaining to supporting adult learners, understanding the essence of studentcentered teaching; they also need to know about those factors leading to increased student satisfaction which, in turn, yields higher persistence rates (Travers, 2016). Research in student retention carried out by Xu and Jaggars (2014) indicated that student learning in the online courses appears to vary based on age. The instructor ought to apply the principles of pedagogy and andragogy to support students who possess various learning styles and demographic characteristics. Student persistence is likely to be negatively impacted if instructors are deficient in the knowledge of pedagogy and andragogy even though they are content experts and proficient in using a variety of technologies (Travers, 2016; Xu and Jaggars, 2014). As stated by Bawa (2016), instructors should also evaluate their own communication, facilitation, and technological skills along with the attempt of refining their competencies if necessary. 


\subsubsection{Support Services}

A large percentage of students who fail to complete online courses is related to the lack of support, including tutoring centers, advisors, technical support, that they can receive on the traditional campus (Travers, 2016). One typical institutional response is to implement structured student support services designed to utilize a holistic approach that is incorporated with cross-department responsibility and addresses both formal and informal student experiences in the intellectual and social life of the institution (Britto and Rush, 2013; Demetriou and Suhmitz-Sciborski, 2011). The underlying assumption is that if an educational institution provides adequate structured opportunities for students to engage with the institution, students will become integrated into the institution and persist at a higher rate. Students taking online courses may not have the opportunity to use these services due to their physical separation from the institution. Support services should be designed to support and be available to online students that are equivalent to traditional student supports (Simonson et al., 2015), which ought to be an ongoing strategy in the institution (Travers, 2016).

Twenty-four/seven technology support and off-hour tutoring are necessary to provide the needed supports to online students (Britto and Rush, 2013; Demetriou and SuhmitzSciborski, 2011; Nandi et al., 2015). In addition, unsuccessful students need more course management assistance to learn the course layout and understand expectations and assignments. Student support services such as providing guidance, counseling, assessment, and coaching are greatly demanded in the online education (Demetriou and Suhmitz-Sciborski, 2011; Nandi et al. 2015). The findings from a study carried out by Nandi et al. (2015) disclosed that it is important to provide administrative or technical guidance early in online courses with an emphasis on the instructors' active involvement in managing the learning processes that ultimately help learners improve their ability to effectively use available resources. Clear and detailed guidelines are also essential to assist the learners to customize their online learning.

Additionally, student advisors have a key role in student persistence as well (Britto and Rush, 2013; Simonson et al., 2015). Students tend to talk to their advisors-not the professors-about their personal life and issues since advisors have built a long-term relationship with students since they first enrolled in the university. Student advisors should be proactive in communicating with students about future course plans and course registration. Ongoing student guidance beyond the course is also critical to student academic success in the online learning environment (Simonson et al., 2015). Overall, the educational institution has a duty to make all relevant information available online and easily accessible to the students. 


\section{Case Study}

\subsection{Background information for the Case Study}

The delivery of distance learning courses in fully online modality is not a new phenomenon in the U.S. higher education. Online courses play a significant role in providing opportunities for adult learners to further their education without sacrificing their work and family commitments. The unit of analysis in this case study is an accredited online university in the United States that offers associate's, bachelor's, and master's degrees to adult learners. The mission of Ashford University $(2017$, p. 1) "is to provide high-quality, accessible, affordable, and innovative, educational programs that meet the diverse needs of individuals pursuing advancement in their lives, professions, and communities." Since its establishment in 2005, Ashford University has striven meeting the needs of diverse learners and supporting student success.

According to the 2017 Distance Education Enrollment Report by Allen and Seaman (2017), about half of the distance learning students were concentrated in a relatively small number (5\%) of the universities between 2012 and 2015. Due to growing competition, new regulation, and government pressure, some largest for-profit institutions were suffering steep declines in enrollment. The change in student enrollments consisted of a relatively few institutions that had large gains or losses. Among those institutions, Ashford University was recorded as one of the largest drops for-profit institutions (Allen and Seaman, 2017). In response to this critical issue, Ashford's Office of Institutional Effectiveness has conducted a number of studies to ascertain the reasons why students depart from Ashford and the findings show that the top three contributing factors are personal or family emergencies and issues, a change in their personal financial situation, and taking a break from studies (Ashford University, 2018).

To tackle these challenges, the University has implemented a variety of interventions aimed at supporting and fostering student success throughout a student's academic experience. Espoused by Tinto's student integration framework, interventions were tested, and the results were analyzed to determine the impacts. Interventions may be maintained, altered, reassessed, or discontinued on the basis of the findings generated from the collected data. Several intervention strategies have demonstrated immediate impacts to students, including the Student Success Orientation, the Ashford Promise, Tutoring on Demand, 24/7 Access to the Library and Writing Center, Finish Line Outreach, Collaborative Holistic and Academic Mentoring for Peer Success, and Top 50 Retention Intervention (Ashford University, 2018). 


\subsubsection{Student Success Orientation (SSO)}

The SSO is a no-cost, not-for-credit, 11-day experience designed to assist adult learners with no previous college experience in making a smooth transition to Ashford. Students enrolled in the SSO include baccalaureate students who bring no credits in transfer, associate's degree students, and students under the age of 22 with fewer than 20 transfer credits. In the SSO, students assess their personal readiness to learn in an online environment. Additionally, they are given the opportunity to connect with academic support resources such as the library and writing center (Ashford University, 2018).

\subsubsection{Ashford Promise}

The Ashford Promise allows students to withdraw from their first course during the first three weeks without any academic and financial repercussions. The Ashford Promise along with SSO enables prospective students to experience the online college environment prior to making a commitment and to develop their capabilities to be successful at Ashford. About $76 \%$ of conditionally admitted applicants persist after the first three weeks. Historically, the denial rate was around $7 \%$. Since the establishment of the Ashford Promise, students are $13 \%$ more likely to progress to nine months of attendance (Ashford University, 2018).

\subsubsection{Tutoring on Demand}

Tutoring on Demand provides just-in-time, live, and no-cost individualized support in 15 courses across several disciplines for example accounting, math, statistics, and research methods. These 15 courses were identified as having posed significant challenges to many learners. The University has performed a Tutoring on Demand analysis to evaluate the effectiveness of this tutoring service. Since its inception in January 2016, the overall dropout rate has decreased by $1 \%$; the fail rate has dropped by $4 \%$; and the pass rate has grown by $5 \%$. Compared to non-users, Tutoring on Demand users have a $10 \%$ higher pass rate and demonstrate a $11 \%$ higher persistence in completing their next four courses (Ashford University, 2018).

\subsubsection{4/7 Access to the Library and Writing Center}

In response to students' active lives and their critical needs, Ashford has offered just-intime solutions, including 24/7 access to the Ashford University Library and Ashford University Writing Center. Students can easily access to the library and writing center from the online classrooms that they enroll. Students can also contact librarians through a live chat feature that is accessible through the library's website. 
Within the library, there is a student support service entitled AskAshford, a knowledge base located on the student portal. AskAshford is available 24/7 and contains answers to questions most frequently asked by students. These questions include financial aid, transcripts, and scheduling, as well as email addresses and other contact information for support staff. Launched on September 26, 2017, a total of 2,786 queries were entered into the system in its first five weeks. Of those, 1,131 queries $(41 \%)$ were directed to a live chat (Ashford University, 2018).

The Ashford Writing Center provides live tutoring and paper assignment review, allowing students to speak with a writing tutor and receive feedback. The paper review highlights a manual review of a student's paper by a writing tutor. The review focuses on the development of writing skills at a higher level. Nearly $50 \%$ of papers are returned to students within 12 hours and the rest within 24 hours. Between February and September 2016, paper review increased $412 \%$ and library sessions increased $25 \%$. Based upon a 14-month analysis of courses that have the paper review, users have higher pass rates, higher three-month persistence rates, better grades, and lower dropout rates compared to those students who choose not to use the service (Ashford University, 2018).

\subsubsection{Finish Line Outreach to Students}

Finish Line Outreach is a retention intervention implemented in the Department of General Education. This intervention identifies "near course completers," students whose grades fall in the range of $57 \%-73 \%$ and who have completed all other coursework with the exception of the final assignment. Thus, the final assignment is critical to a passing/failing grade if students do or do not submit the final work. In coordination with student advisors, faculty members reach out to the near course completers and provide additional time to complete the final assignment. Since its implementation, this intervention has benefited more than 600 students in courses, for example, math and several other general education courses. The results from this assessment study show a $69 \%$ success rate (Ashford University, 2018).

\subsubsection{Collaborative Holistic and Academic Mentoring for Peer Success (CHAMPS)}

CHAMPS peer mentoring is a seven-week outreach program that matches new students with successful Ashford student peers who help new students navigate through their first and second courses. This program also offers more personalized peer-matching for specific student populations such as military and veteran student participants. By differentiating the CHAMPS experience for these students, the university ensures militaryaffiliated students and student veterans are connected to fellow students who understand 
the unique challenges that they face, including the impacts of multiple deployments on military families and the transition from military to civilian life. This program not only promotes new student success for mentees but also provides leadership development opportunities for mentors. Results generated from the CHAMPS mentoring program demonstrate that it has a positive impact on student progression. For instance, students who completed the program had a higher progression rate about $9 \%$ at the end of the program and kept that advantage at week 15 toward the end of the program (Ashford University, 2018).

\subsubsection{Top 50 Retention Intervention}

The Top 50 Retention Intervention is a collaboration between the faculty and the academic staff, student support departments, and the Office of Institutional Effectiveness. It is a team effort to design and test data-informed improvements to the university's 50 courses that have the highest enrollments and lowest retention rates. Interventions have included closer reviews of faculty expertise in a course; greater full-time and part-time faculty collaboration; additional professional development offerings; proliferation of successful, scalable piloted approaches to best practices in teaching; and development of specific instructional assets for courses. These efforts generated a $2.4 \%$ increase in course pass rates, a $0.7 \%$ decrease in failure rates, and a $1.7 \%$ reduce in drop rates (Ashford University, 2018).

\section{Discussion}

In the past decade, demographic shift, global economy, political upheaval, and technological innovation have triggered disruptions virtually every sector of the society, including the higher education system in the United States. From the perspective of the traditional higher education, there are numerous examples of disruptions, for instance, the growth of online programs, competency-based education, the demise of the traditional textbook, and the increasing acceptance of open educational resources (Ashford University, 2018). The affordability and accessibility of higher education has become an imperative topic discussed by the academic leaders. Leaders of successful institutions must be able to accept the reality and forge a shared vision for the future that embraces transformative change.

Since its establishment in 2005, Ashford University's online teaching, learning, and student support model has provided a strong and viable foundation. Ashford has also consistently implemented incremental change and introduced innovations to maintain the model's currency and relevance, which has represented good practices in online education. Due to the significant decrease in student enrollment from the years of 2014 and 2015, the university leaders responded to this critical issue by examining the potential consequences 
of larger forces that drive the significant changes in higher education. This urgent desire from the leadership was to ensure the institution's continued relevance and viability as well as maintain conformity to the Ashford mission. Ashford has implemented and tested a variety of interventions that signify important steps toward realization of the leadership's vision.

Ashford has directed its efforts and resources on improving student retention and success. Despite the fact that the university's efforts have not yielded the hoped-for gains, the university's faculty and administrative leaders remain committed to serving those students who have come to the institution with the intent of completing a postsecondary degree. Even though declining enrollment challenges the institution financially, Ashford continues to strength approaches to scaffolding services around students to meet their individual needs. It is critical to the future that Ashford persists to create learning environments that engage, motivate, and support learning and students in new ways, which in turns benefit to the public good.

\section{Conclusion}

Online courses and programs have grown dramatically and extended the educational opportunities to diverse adult learners who never would have the opportunity or inclination to take classes on campus. Online learning is appealing because it increases course choices, decreases time and costs associated with commuting, and provides greater access to education. Among these adult learners, some are working professionals who have multiple responsibilities and commitments while others are those who were least wellserved by traditional educational institutions. Despite the popularity of online learning, the high dropout rates have been a serious concern for educators and institutions. In response to these concerns, online education has made great strides in recent years to improve the service quality and better respond to labor market needs. Offering student support services, providing useful course work, engaging students, and building the skills necessary for the workforce are particularly important.

Knowledge is power. With knowledge, individuals can cultivate their lives and change the world for a better future. Making education accessible is critical in today's information age. Since adult learners come from varied backgrounds and take online courses or programs for various reasons, they may embark on different pathways to complete the course and/or program. Thus, the online universities need to continue to work vigorously to increase student retention and completion rates. Recognizing and supporting each student's personal, academic, and professional goals should be the institution's long-term strategic planning. An ongoing comprehensive monitoring system will not only help the institution to predict who is more likely to drop out and invest the needed resources, but also shed the 
insights on the effectiveness of interventions so as to reap the maximin benefits-thereby increasing student satisfaction and success.

\section{References}

ALLEN, I. E. and SEAMAN, J. (2015). Grade Level: Tracking Online Education in The United States. The Babson Survey Research Group, OLC, Pearson and Tyton Partners. Retrieved from http://www.onlinelearningsurvey.com/reports/gradelevel.pdf

ALLEN, I. E. and SEAMAN, J. (2015). Digital Learning Compass: Distance Education Enrollment Report 2017.

Retrieved

from

https://onlinelearningsurvey.com/reports/digtiallearningcompassenrollment2017.pdf

ASHFORD UNIVERSITY. (2016.) Ashford University 2017 -2018 Academic Catalog. Retrieved from http://wpc.6fdc.edgecastcdn.net/006FDC/AU/catalog/2017/2017-

2018\%20Ashford\%20University Full\%20Catalog-for\%20web.pdf

ASHFORD UNIVERSITY. (2018). 2018 WSCUC Institutional Report. San Diego, CA: Ashford University.

BART, M. (2012). Online Student Engagement Tools and Strategies. Faculty Focus. Retrieved from http://www.facultyfocus.com/free-reports/online-student-engagement-tools-and-strategies/

BOWERS, J. and KUMAR, P. (2015). Students' Perceptions of Teaching and Social Presence: A Comparative Analysis of Face-To-Face and Online Learning Environments. Web-Based Learning and Teaching Technologies. 2015, Vol. 10, p. 27-44. doi: 10.4018/ijwltt.2015010103

BRITTO, M. and RUSH, S. (2013). Developing and Implementing Comprehensive Student Support Services for Online Students. Journal of Asynchronous Learning Networks. 2013, Vol. 17, No. 1, p. 29-42.

CHRISTENSEN, S. S. and SPACKMAN, J. S. (2017). Dropout Rates, Student Momentum, and Course Walls: A New Tool for Distance Education Designers. The Journal of Educators Online. July 2017, Vol.14, No. 2. Retrieved from https://files.eric.ed.gov/fulltext/EJ1150708.pdf

COCHRAN, J. D.; CAMPBELL, S. M.; BAKER, H. M. and LEES E. M. (2014). The Role of Student Characteristics in Predicting Retention in Online Courses. Research in Higher Education, vol. 55, p. 122. doi: $10.1007 / \mathrm{s} 11162-013-9305-8$

COONER, S.L.; DAUGHERTY, D. A. and GILMORE, M.N. (2013). Student Retention and Persistence to Graduation: Effect of An Introductory Life Calling Course. Journal of College Student Retention: Research, Theory \& Practice. 2013, Vol. 14, No. 2, p. 251-263. https://doi.org/10.2190/CS.14.2.f

DEMETRIOU, C. and SCHMITZ-SCIBORSKI, A. (2011). Integration, Motivation, Strengths and Optimism: Retention Theories Past, Present and Future. In R. Hayes (Ed.), Proceedings of the 7th National Symposium on Student Retention, 2011, Charleston. (pp. 300-312). Norman, OK: The University of Oklahoma. 
HILL, P. (2018, January 3). Fall 2016 IPEDS First Look: Continued Growth in Distance Education in US. Retrieved from https://mfeldstein.com/fall-2016-ipeds-first-look-continued-growth-distance-educationus/

JAMES, S.; SWAN, K. and DASTON, C. (2016). Retention, Progression, and The Taking of Online Courses. Online Learning, Vol. 20, No. 2. Retrieved from http://onlinelearningconsortium.org/

JAGGARS, S. S. (2011). Online Learning: Does It Help Low-Income and Underprepared Students? (CCRC Working Paper No. 26). New York, NY: Community College Research Center, Columbia University.

LEE, Y. and CHOI, J. (2013). A Structural Equation Model of Predictors of Online Learning Retention. Internet and Higher Education, 2013, Vol. 16, p. 36-42. doi:10.1016/j.heduc.2012.01.005

LAMMERS, W. J. and GILLASPY, J. A., Jr. (2013). Brief measure of student-instructor rapport predicts student success in online courses. International Journal for the Scholarship of Teaching and Learning. 2013, Vol. 7, No. 2, article 16. https://doi.org/10.20429/ijsotl.2013.070216

LU, H. (2017). Sustainability of E-Learning Environment: Can Social Presence Be Enhanced by Multimedia? International Journal of Information and Education Technology. 2017, Vol. 7, No. 4, p. 291-296. doi: 10.18178/ijiet.2017.7.4.883

NANDI, D.; HAMILTON, M.; HARLAND, J. and MAHMOOD, S. (2015). Investigation of Participation and Quality of Online Interaction. I. J. Modern Education and Computer Science. 2015, Vol. 8, p. 25-37. doi: 10.5815/ijmecs.2015.08.04

NASH, J. A. (2015). Future of online education in crisis: A call to action. The Turkish Online Journal of Educational Technology. 2015, Vol.14, No. 2, p. 80-88.

POLL, K.; WIDEN, J. and WELLER, S. (2014). Six Instructional Best Practices for Online Engagement and Retention. Journal of Online Doctoral Education. 2014, Vol. 1, No. 1, p. 56-72.

RITTER, C.; POLNICKA, B.; FINK, R. and OESCHER, J. (2010). Classroom Learning Communities in Educational Leadership: A Comparison Study of Three Delivery Options. Internet and Higher Education. 2010, Vol. 13, No. 1-2, p. 96-100. Doi: http://dx.doi.org/10.1016/j.iheduc.2009.11.005

SAFFORD, K. and STINTON, J. (2016). Barriers to Blended Digital Distance Vocational Learning for Nontraditional Students. British Journal of Educational Technology. 2016, Vol. 47, No. 1, p. 135-150. https://doi.org/10.1111/bjet.12222

SIMONSON, M.; SMALDINO, S. and ZVACEK, S. (2015). Teaching and Learning at a Distance: Foundations of Distance Education (6th ed.). Charlotte, NC: Information Age. ISBN-10: 0132487314

SOUTHERN REGIONAL EEDUCATION BOARD. (n.d.). Who is The Adult Learner? Retrieved from http://www.sreb.org/page/1397/who_is_the_adult_learner.html

TAIPJUTORUS, W.; HANSEN, S. and BROWN, M. (2012). Investigating a Relationship Between Learner Control and Self-Efficacy in An Online Learning Environment. Journal of Open, Flexible and Distance 
Learning. 2012, Vol.16, No. 1, p. 56-69. Retrieved from http://www.jofdl.nz/index.php/JOFDL/article/view/95

THOMAS, L.; HERBERT, J. and TERAS, M. (2014). A Sense of Belonging to Enhance Participation, Success and Retention in Online Programs. The International Journal of the First Year in Higher Education. 2014, Vol. 5, No. 2, p. 69-80. doi: 10.5204/intjfyhe.v5i2.233

TINTO, V. (1975). Dropouts from Higher Education: A Theoretical Synthesis of Recent Literature. A Review of Educational Research. 1975, Vol. 45, No. 1, p. 89-125. doi: 10.2307/1170024

TINTO, V. (1987). From Theory to Action: Exploring the Institutional Conditions for Student Retention. In J.C. Smart (ed.), Higher Education: Handbook of Theory and Research. 1987, Vol. 25, p. 51-89. Chicago, IL: The University of Chicago. Doi: 10.1007/978-90-481-8598-6_2,

TINTO, V. (1993). Leaving College: Rethinking the Causes and Cures of Student Attrition (2nd ed.). Chicago, IL: University of Chicago Press.

TINTO, V. (1999). Taking Retention Seriously: Rethinking the First Year of College. NACADA Journal. 1999, Vol. 19, No. 2, p. 5-9. https://doi.org/10.12930/0271-9517-19.2.5

TINTO, V. (2007). Research and Practice of Student Retention: What Next? Journal of College Student

Retention: Research, Theory \& Practice. 2007, Vol. 8, No. 1, p. 1-19. https://doi.org/10.2190/4YNU-4TMB22DJ-AN4W

TRAVERS, S. (2016). Supporting Online Student Retention in Community Colleges. What Data Is Most Relevant? The Quarterly Review of Distance Education. 2016, Vol. 17, No. 4, p. 49-61.

XU D. and Jaggars, S. S. (2014). Performance Gaps between Online and Face-To-Face Courses: Differences Across Types of Students and Academic Subject Areas. The Journal of Higher Education. 2014, Vol. 85, No. 5, p. 634-659. https://doi.org/10.1353/jhe.2014.0028 